\title{
SEGURANÇA DOS ALIMENTOS NO CONTEXTO DA PANDEMIA POR SARS-COV-2
}

Food safety in the context of the SARS-CoV-2 pandemic

Seguridad alimentaria en el contexto de la pandemia de SARS-CoV-2

\section{Hermanny Matos Silva Sousa*1, Andréia Ibiapina ${ }^{1}$, Adriene Ribeiro Lima ${ }^{2}$, Glêndara Aparecida de Souza Martins ${ }^{1}$}

${ }^{1}$ Laboratório de Cinética e Modelagem de Processos, Engenharia de Alimentos, Universidade Federal do Tocantins, Palmas, Brasil.

${ }^{2}$ Departamento de Bromatologia, Faculdade de Farmácia, Universidade Federal Fluminense, Niterói, Brasil.

*Correspondência: Laboratório de Cinética e Modelagem de Processos, Universidade Federal do Tocantins, Engenharia de Alimentos, Av. NS 15, 109 Norte, Palmas, Tocantins, Brasil. CEP:77.010-090. e-mail hermanny_97@hotmail.com.

\section{RESUMO}

O mundo está enfrentando uma pandemia que teve como epicentro a cidade de Wuhan, na China, e se espalhou pelo mundo todo. Vários países estão em estado de alerta por se tratar de uma pandemia causada por um vírus com causas e consequências ainda desconhecidas. O vírus é o SARS-CoV2, da família Coronaviridae, onde o SARS-CoV, já ocasionou uma pandemia em 2003, deixando mais de 700 mortos ao redor do mundo. O novo coronavírus, causador da doença denominada COVID-19, afeta principalmente o sistema respiratório e tem uma taxa de transmissão muito alta. Alguns pacientes podem ser assintomáticos, culminando numa alta capacidade de transmissão. Dados científicos comprovam que esse vírus permanece em atividade durante horas, em alguns materiais, trazendo preocupação com a segurança dos alimentos e o questionamento quanto ao contágio através da alimentação. Por isso, é necessário o cuidado na manutenção e higienização das instalações, equipamentos e utensílios, atendendo às Boas Práticas para garantir a segurança sanitária dos alimentos.

Palavras-chave: Alimentação; Segurança; Pandemia.

\section{ABSTRACT}

The world is facing a pandemic that had the epicenter of the city of Wuhan, China, and has spread around the world. Several countries are on alert because it is a pandemic caused by a virus with causes and consequences still unknown. The virus is SARS-CoV2, of the Coronaviridae family, where SARS-CoV has already caused a pandemic in 2003, leaving more than 700 dead worldwide. The new coronavirus, which causes the disease called COVID-19, mainly affects the respiratory system and has a very high transmission rate. Some patients may be asymptomatic, resulting in a high transmission capacity. Scientific data prove that this virus remains active for hours, in some materials, raising concerns about food safety and the questioning of contagion through food. For this reason, care is required in the maintenance and hygiene of facilities, equipment and utensils, in compliance with Good Practices to ensure food safety.

Keywords: Food; Safety; Pandemic.

\section{RESUMEN}

El mundo enfrenta una pandemia que tuvo el epicentro de la ciudad de Wuhan, China, y se ha extendido por todo el mundo. Varios países están en alerta porque es una pandemia causada por un virus con causas y consecuencias aún desconocidas. El virus es SARS-CoV2, de la familia Coronaviridae, donde el SARS-CoV ya ha causado una pandemia en 2003, dejando más de 700 muertos en todo el mundo. El nuevo coronavirus, que causa la enfermedad llamada 
COVID-19, afecta principalmente al sistema respiratorio y tiene una tasa de transmisión muy alta. Algunos pacientes pueden ser asintomáticos, lo que resulta en una alta capacidad de transmisión. Los datos científicos demuestran que este virus permanece activo durante horas, en algunos materiales, lo que genera preocupaciones sobre la seguridad alimentaria y el cuestionamiento del contagio a través de los alimentos. Por esta razón, se requiere cuidado en el mantenimiento e higiene de las instalaciones, equipos y utensilios, de conformidad con las Buenas Prácticas para garantizar la seguridad alimentaria.

Descriptores: Alimentación; Seguridad; Pandemia.

\section{INTRODUÇÃO}

Os coronavírus (CoVs) são organismos microscópicos pertencentes a uma grande família de vírus de RNA de fita simples, que podem infectar animais e humanos, causando doenças respiratórias, gastrointestinais, hepáticas e neurológicas (Wu et al., 2020).

Os subgrupos da família Coronaviridae são coronavírus alfa $(\alpha)$, beta $(\beta)$, gama $(\gamma)$ e delta $(\delta)$. O coronavírus da síndrome respiratória aguda grave (SARS-CoV), e o coronavírus da síndrome respiratória do Oriente Médio (MERS-CoV) causam lesão pulmonar aguda e síndrome do desconforto respiratório agudo, que leva à insuficiência pulmonar e pode resultar em fatalidades (Lai et al., 2020; Shereen et al., 2020).

Em 2003, o SARS-CoV, infectou 8098 pessoas e deixou 776 mortes, em 26 países do mundo (Shereen et al., 2020).

No final de 2019, Wuhan, Província de Hubei, um centro comercial emergente da China, sofreu um surto epidemiológico, causando pneumonia de causa desconhecida nos pacientes. O patógeno, um novo coronavírus (SARS-CoV-2), foi identificado pelos hospitais locais usando um mecanismo de vigilância para "pneumonia de etiologia desconhecida" que foi estabelecida após o surto de SARS de 2003, com o objetivo de permitir a identificação oportuna de novos patógenos (Li-Q et al., 2020).

O novo coronavírus matou mais 1800 e infectou mais de 70000 pessoas nos primeiros cinquenta dias da epidemia, um gráfico exponencial preocupante. Foi relatado que este vírus é um membro do grupo $\beta$ de coronavírus (Cui et al., 2019).

O Comitê Internacional de Taxonomia de Vírus (ICTV) nomeou o vírus como SARS-CoV-2 e a doença como COVID-19 (Lai, et al., 2020; OMS-a, 2020). Em 30 de janeiro de 2020, a Organização Mundial da Saúde (OMS) declarou que o COVID-19 é uma "emergência de saúde pública de interesse internacional" (Li-X et al., 2020) e, por esse motivo, as diversas formas de transmissão começaram a ser investigadas e os questionamentos no âmbito da segurança dos alimentos passaram a ser frequentes.

Nesse contexto, é reportado pela literatura que uma grande variedade de vírus, causadores de infecções, podem ser transmitidos através de alimentos em todo o mundo. (Miranda e Schaffner, 2019).

A maioria dos vírus veiculados por alimentos não possuem envelope viral o que os torna extremamente estáveis no ambiente. $\mathrm{O}$ envelope viral por ser constituído de proteínas e lipídeos, é sensível a detergentes, a alguns agentes antimicrobianos e às técnicas de processamento como o uso de altas ou baixas temperaturas. Portanto, os vírus não envelopados podem sobreviver nas superfícies/cascas dos alimentos, mãos, fezes e superfícies de contato com alimentos por longos períodos de tempo (Miranda e Schaffner, 2019).

Diante desse cenário, o presente trabalho traz um levantamento bibliográfico no âmbito da transmissão do vírus SARS-CoV-2 por alimentos, considerando a atual pandemia vivida e seus desdobramentos. 


\section{TRANSMISSÃO DO SARS-CoV-2 E VEICULAÇÃO POR ALIMENTOS \\ É importante determinar a fonte de origem e} transmissão de um vírus para desenvolver estratégias preventivas para conter a infecção. No caso do SARS$\mathrm{CoV}$, os pesquisadores inicialmente se concentraram em animais selvagens e morcegos que são considerados como hospedeiros naturais $\mathrm{e}$ desempenham um papel crucial na transmissão de vários vírus, incluindo Ebola, Nipah, Coronavírus e outros (Malik et al., 2020).

O SARS-CoV-2 é o sétimo membro da família Coronaviridae, que é o beta-CoV com mais de $70 \%$ de semelhança na sequência genética de SARS-CoV (Cheng e Shan, 2020).

Como SARS-CoV, MERS-CoV e muitos outros coronavírus, o SARS-CoV-2 provavelmente se originou em morcegos, mas requer confirmação adicional se a pneumonia é causada devido a infecção pelo SARS-CoV-2 transmitida diretamente dos morcegos ou por meio de um hospedeiro intermediário (Jin et al., 2020).

Pesquisa recente relata que o genoma do SARS-CoV-2 é $96 \%$ idêntico ao genoma do coronavírus que infecta morcegos, o que significa que o morcego é o hospedeiro mais provável do SARSCoV-2 (Zhou et al., 2020). Além disso, Ji et al., (2020) demonstraram que o morcego é um possível reservatório de vírus para infecção humana. Cheng e Shan (2020) indicaram que morcegos e martas talvez sejam os hospedeiros em potencial do novo coronavírus podendo ser os hospedeiros intermediários desse vírus.

Para muitos vírus, uma das principais etapas do processo de disseminação interespécies é o salto dos animais para os seres humanos. Assim, identificar a fonte do vírus ajudará a controlar sua propagação (Perlman, 2020).
Em 12 de janeiro de 2020, a Comissão E Nacional de Saúde da China divulgou mais detalhes sobre a epidemia, sugerindo pneumonia viral (Wang et al., 2020). A partir da análise sequencial de isolados dos pacientes foi possível identificar o vírus como um novo coronavírus. Além disso, a sequência genética também foi fornecida para o diagnóstico de infecção viral.

Inicialmente, sugeriu-se que os pacientes infectados com coronavírus que desenvolveram pneumonia viral em Wuhan na China pudessem ter visitado o mercado de frutos do mar onde os animais vivos foram vendidos ou podem ter consumido animais ou pássaros infectados (Phan et al., 2020). No entanto, investigações posteriores revelaram que alguns indivíduos desenvolveram a infecção, mesmo sem registro de visitar o mercado de frutos do mar. Essas observações indicaram à capacidade de disseminação humana desse vírus, que foi posteriormente relatada em mais de 100 países do mundo.

Nesse contexto, infecções alimentares estão relacionadas a doenças ocasionadas pela ingestão de alimentos contendo microrganismos patogênicos viáveis. No caso de vírus, ocorreria infecção, pois utilizam a célula do hospedeiro para sua multiplicação (Both, 2018).

As Doenças Transmitidas por Alimentos (DTA) são caracterizadas por sintomas como náusea, vômito, diarreia, febre, e que podem evoluir para sintomas extraintestinais. Essa contaminação pode ocorrer através da ingestão de água ou alimentos contaminados (Melo et al., 2018).

Uma grande variedade de vírus pode ser transmitida por alimentos. Esses vírus pertencem a numerosas famílias diferentes que podem causar doenças neurais graves, paralisia flácida, com eventos até raros de miocardite, doença respiratória ou febre hemorrágica. No entanto, as doenças virais veiculadas Revista Desafios - v7, n. Supl. COVID-19, 
por alimentos mais frequentemente relatadas são gastroenterite e hepatite (Bosch et al., 2016).

De maneira geral, os surtos de doenças transmitidos por alimentos causados por patógenos microbianos sobrecarregam o sistema de saúde, não apenas por meio das doenças, mas também pelos custos associados às medidas tomadas para reduzir os impactos sobre a população (Bosch et al., 2018; Both, 2018).

Consequentemente, os vírus transmitidos por alimentos são reconhecidos como relevantes no contexto de segurança dos alimentos em um relatório recente de especialistas em avaliação de risco (Rowe e Bolger, 2016). Assim, nos últimos anos, os vírus veiculados por alimentos tornaram-se uma preocupação maior para a indústria de alimentos e para os órgãos reguladores. Por esse motivo, as viroses alimentares começaram a ser rotineiramente monitoradas em sistemas de vigilância, entretanto, esse monitoramento é realizado apenas em alguns países industrializados (Bosch et al., 2018).

A Autoridade Europeia de Segurança dos Alimentos (European Food Safety Authority - EFSA, 2020) está monitorando de perto a situação do surto da COVID-19 que está atingindo muitos países em todo o mundo. No entanto, atualmente, não há evidências de que os alimentos sejam uma fonte ou via provável de transmissão do SARS-CoV-2.

De acordo com o Instituto Federal de Avaliação de riscos da Alemanha (Bundesinstitut fur Risikobewertung), não há casos que tenham demonstrado qualquer evidência de humanos infectados com o novo tipo de coronavírus por outras vias de transmissão, como o consumo de alimentos contaminados. Também não há relatos científicos de outros coronavírus envolvidos em processos infecciosos que tivessem sido veiculados por alimentos (BfR, 2020).
Embora não haja comprovação de que o vírus seja transmitido por alimentos contaminados, regras gerais de higiene cotidiana, como lavagem regular das mãos e regras de higiene para a preparação de alimentos, devem ser observadas. Como os vírus são sensíveis ao calor, o risco de infecção também pode ser reduzido em alimentos que sofrem processos térmicos a altas temperaturas (OMS-b, 2020).

Apesar de até o momento não haver evidências de cadeias de infecção por SARS-CoV-2 através do consumo de alimentos, incluindo alimentos congelados, sabe-se que os coronavírus anteriores SARS e MERS, são resistentes a temperaturas de congelamento e podem permanecer infecciosos a menos 20 graus Celsius por até 2 anos. Este fato levanta a hipótese de que o SARS-CoV-2 possui as mesmas características estruturais dos outros vírus da mesma família, apresentando resistência ao frio. Assim, o cumprimento das regras gerais de higiene para a preparação de alimentos deve ser levado em consideração (BfR, 2020).

Alguns vírus de origem alimentar, podem ser encontrados em números muito elevados $\left(10^{5}\right.$ $10^{11}$ partículas de vírus / g de fezes ou do vômito) a partir de indivíduos infectados, e têm uma dose infecciosa mediana relativamente baixa, o que pode conduzir a grandes surtos em curtos períodos de tempo (Sabrià et al., 2016). Como os vírus são importantes agentes etiológicos envolvidos em surtos alimentares, houve um progresso significativo nos últimos anos em relação às metodologias disponíveis para detecção e identificação de vírus em alimentos e amostras clínicas (Souza, 2015).

Os alimentos servidos crus ou levemente cozidos são considerados de maior risco na propagação de doenças virais entéricas. Mariscos, frutas e legumes frescos estão entre os alimentos mais comumente relacionados a surtos de vírus transmitidos 
por alimentos (Iritani et al., 2014; Callejón et al., 2015).

As frutas e legumes frescos normalmente passam por pouco ou nenhum processamento e podem ser contaminados a qualquer momento, desde a précolheita até a pós-colheita. As principais rotas de contaminação incluem água contaminada para irrigação ou lavagem, ou por trabalhadores infectados que manipulam os alimentos durante a colheita, processamento ou distribuição (Aw et al., 2016).

Os vírus têm propriedades que os tornam bem diferentes dos patógenos bacterianos transmitidos por alimentos mais comumente estudados. Nesse âmbito, destaca-se que os vírus não têm vida livre e são capazes de se replicar apenas dentro das células vivas de humanos, outros animais, plantas ou bactérias. Desta maneira, os vírus transmitidos por alimentos são incapazes de se multiplicar nos alimentos pois necessitam de um organismo vivo para se replicar. Porém, eles podem sobreviver muito tempo em inatividade nas superfícies dos alimentos a fim de encontrar um hospedeiro, por meio de uma contaminação cruzada, ocasionando assim infecções (Miranda e Schaffner, 2019).

\section{TRANSMISSÃO POR EMBALAGENS E SUPERFICIES DE CONTATO}

É sabido que a disseminação do vírus entre os humanos ocorre devido ao contato próximo com uma pessoa infectada, exposta à tosse, espirros, gotículas respiratórias ou aerossóis. Esses aerossóis podem penetrar no corpo humano (pulmões) por inalação pelo nariz ou pela boca, tornando essas gotículas respiráveis a principal via de transmissão. Contudo, a contaminação cruzada pode ocorrer uma vez que a taxa de sobrevivência desse vírus pode ser alta em superfícies como aço inoxidável e plástico (até 72 horas), papelão e cobre (até 4 horas) (Riou e Althaus, 2020; Parry, 2020; Van Doremalen et al., 2020). DOI: http://dx.doi.org/ 10.20873/uftsuple2020-8771 2020
Tendo em vista a utilização desses materiais na indústria de alimentos, principalmente o aço inoxidável que compõe a maioria dos utensílios, e o plástico, presente na maioria das embalagens alimentícias, essa pode ser uma preocupação quanto aos alimentos que possam ser contaminados através desses meios que não passam por processos de alta temperatura.

Adotar as Boas Práticas de Fabricação (BPF) durante o processamento de alimentos é de suma importância, uma vez que a limpeza e desinfecção de superfícies e utensílios, assim como dos alimentos, auxiliam a atividade antimicrobiana, destruindo a membrana que envolve o SARS-CoV-2, membrana esta que é composta de proteínas e lipídeos. O uso de água e sabão e o uso de álcool $70 \%$ trazem excelentes resultados na desnaturação das proteínas e dissolução de lipídeos, no entanto, esses produtos devem ser utilizados para a higienização das mãos, utensílios e superfícies, e não para a desinfecção de alimentos (Oliveira et al., 2020; Santos et al., 2018). Para a desinfecção de alimentos, em especial hortifruti (frutas, legumes e verduras), deve-se imergir os alimentos em uma solução preparada com $10 \mathrm{ml}$ (1 colher de sopa) de hipoclorito de sódio a 2,5\% para cada litro de água tratada (diluição de 200 ppm), eliminando os possíveis patógenos dos alimentos, incluindo o SARS-CoV-2 (Brasil, 2014; Feliziani et al., 2016).

No Brasil, a Lei n. 13.979, de 6 de fevereiro de 2020, regula medidas de quarentena e isolamento, visando o achatamento da curva de transmissão do novo coronavírus (Ventura, et al., 2020). Com isso, muitos empreendimentos passaram a adotar o serviço de delivery para amenizar tanto os danos econômicos que enfrentarão com essa pandemia, quanto os danos para os consumidores que queiram desfrutar dos serviços. Porém, esses serviços devem tomar todos os cuidados possíveis para que não haja transmissão Revista Desafios - v7, n. Supl. COVID-19, 
durante as entregas realizadas, não só por meio das embalagens utilizadas, mas também pela manipulação inadequada nos estabelecimentos alimentícios.

\section{CONCLUSÃO}

São necessários estudos mais aprofundados sobre a possível transmissão do novo coronavírus através de alimentos ou de suas embalagens, pois há probabilidade de ocorrer contaminação cruzada entre utensílios e alimentos durante o processamento, manipulação e/ou consumo dos mesmos. Seguir rigorosamente as BPF impostas pelas legislações vigentes e descritas pelos profissionais da área são de extrema importância para que não ocorra a propagação de microrganismos que comprometam a segurança dos alimentos, sejam eles coronavírus ou qualquer outro microrganismo capaz de causar doenças ao consumidor.

Todos os autores declararam não haver qualquer potencial conflito de interesses referente a este artigo.

\section{REFERÊNCIAS}

AW, T. G.; WENGERT, S.; ROSE, J. B. Metagenomic analysis of viruses associated with field-grown and retail lettuce identifies human and animal viruses. International journal of food microbiology, 223, 50-56. 2016.

BfR, 2020 - Bundesinstitut fur Risikobewertung (Instituto Federal de Avaliação de riscos da Alemanha). Can the new type of coronavirus be transmitted via food and objects? Disponível em: https://www.bfr.bund.de/en/can_the_new_type_of_co ronavirus_be_transmitted_via_food_and_objects_244090.html. Acesso em: 22 de março de 2020.

BOSCH, A.; GKOGKA, E.; LE GUYADER, F. S.; LOISY-HAMON, F.; LEE, A.; VAN LIESHOUT, L.; WINKLER, A. Foodborne viruses: Detection, risk assessment, and control options in food processing. International journal of food microbiology, 285, 110-128. 2018.

BOSCH, A.; PINTÓ, R.M.; GUIX, S. Foodborne viroses. Current opinion in food Science, v.8, p.110119. 2016.
BOTH, J. M. C. A desinfecção como barreira sanitária na prevenção de Doenças Transmitidas por Alimentos (DTA): sensibilidade de amostras de Staphylococcus aureus isoladas em alimentos no IPB-LACEN/RS, nos anos de 2002 a 2006, frente ao hipoclorito de sódio [Internet]. Vol. 36. Acta Scientiae Veterinariae, 77. 2018.

BRASIL. Ministério da saúde. Casos coronavírus no Brasil. Disponível em: https://www.saude.gov.br/noticias/agencia-saude/.

Acesso em: 30 de março de 2020.

BRASIL. Ministério da Saúde. Corona vírus (COVID-19): Orientações gerais. [Ministério da Saúde], 2014.

CALLEJÓN, R. M.; RODRIGUEZ-NARANJO, M. I.; UBEDA, C.; HORNEDO-ORTEGA, R.; GARCIAPARRILLA, M. C.; TRONCOSO, A. M. Reported foodborne outbreaks due to fresh produce in the United States and European Union: trends and causes. Foodborne pathogens and disease, 12(1), 32-38. 2015.

CHENG, Z.J.; SHAN, J. Novel coronavirus: where we are and what we know. Infection, p. 1-9. 2020.

CUI, J.; LI, F.; SHI, Z. L. Origin and evolution of pathogenic coronaviruses. Nature reviews Microbiology, 17(3), 181-192. 2019.

EFSA, 2020 - European Food Safety Authority (Autoridade Europeia de Segurança dos Alimentos). Coronavirus: no evidence that food is a source or transmission route. Disponível em: https://www.efsa.europa.eu/en/news/coronavirus-noevidence-food-source-or-transmission-route. Acesso em: 22 de março de 2020.

FELIZIANI, E., LICHTER, A., SMILANICK, J. L., \& IPPOLITO, A. Disinfecting agents for controlling fruit and vegetable diseases after harvest. Postharvest Biology and Technology, 122, 53-69. 2016.

FUNG, T.S.; LIU, D. X. Human Coronavirus: HostPathogen Interaction. Annual review of microbiology, v. 73, p. 529-557. 2019.

HOLSHUE, M. L.; DEBOLT, C.; LINDQUIST, S.; LOFY, K. H.; WIESMAN, J.; BRUCE, H.; DIAZ, G. First case of 2019 novel coronavirus in the United States. New England Journal of Medicine. 2020. 
IRITANI, N.; KAIDA, A.; ABE, N.; KUBO, H.; SEKIGUCHI, J. I.; YAMAMOTO, S. P.; NODA, M. Detection and genetic characterization of human enteric viruses in oyster-associated gastroenteritis outbreaks between 2001 and 2012 in Osaka City, Japan. Journal of medical virology, 86(12). 2014.

JI, W., WANG, W., ZHAO, X., ZAI, J., \& LI, X. Homologous recombination within the spike glycoprotein of the newly identified coronavirus may boost cross-species transmission from snake to human. J. Med. Virol. 2020.

JIN, Y. H., CAI, L., CHENG, Z. S., CHENG, H., DENG, T., FAN, Y. P., ... \& HAN, Y. A rapid advice guideline for the diagnosis and treatment of 2019 novel coronavirus (2019-nCoV) infected pneumonia (standard version). Military Medical Research, 7(1), 4. 2020.

LAI, C. C.; SHIH, T. P.; KO, W. C.; TANG, H. J.; HSUEH, P. R. Severe acute respiratory syndrome coronavirus 2 (SARS-CoV-2) and corona virus disease-2019 (COVID-19): the epidemic and the challenges. International journal of antimicrobial agents, 105924. 2020.

LANA, R. M.; COELHO, F. C.; GOMES, M. F. D. C.; CRUZ, O. G.; BASTOS, L. S.; VILLELA, D. A. M.; CODECO, C. T. Emergência do novo coronavírus (SARS-CoV-2) e o papel de uma vigilância nacional em saúde oportuna e efetiva. Cadernos de Saúde Pública, 36, e00019620. 2020.

LI, Q.; GUAN, X.; WU, P.; WANG, X.; ZHOU, L.; TONG, Y.; XING, X. Early transmission dynamics in Wuhan, China, of novel coronavirus-infected pneumonia. New England Journal of Medicine. 2020 .

LI, X.; WANG, W.; ZHAO, X.; ZAI, J.; ZHAO, Q.; LI, Y.; CHAILLON, A. Transmission dynamics and evolutionary history of 2019-nCoV. Journal of Medical Virology. 2020.

LUK, H. K.; LI, X.; FUNG, J.; LAU, S. K.; WOO, P. C. Molecular epidemiology, evolution and phylogeny of SARS coronavirus. Infection, Genetics and Evolution. 2019.

MALIK, Y. S.; SIRCAR, S.; BHAT, S.; SHARUN, K.; DHAMA, K.; DADAR, M.; CHAICUMPA, W. Emerging novel Coronavirus (2019-nCoV)-Current scenario, evolutionary perspective based on genome analysis and recent developments. Veterinary Quarterly. 2020.
MELO, E. S.; AMORIM, W. R.; PINHEIRO, R. E. E.; CORRÊA, P. G. N.; CARVALHO, S. M. R.; SANTOS, A. R. S. S.; SOUSA, F. V. Doenças transmitidas por alimentos e principais agentes bacterianos envolvidos em surtos no Brasil. PUBVET, 12, 131. 2018.

MIRANDA, R. C.; SCHAFFNER, D. W. Virus risk in the food supply chain. Current Opinion in Food Science, 30, 43-48. 2019.

OLIVEIRA, A. M. C.; SOUSA, P. V.; ALVES, A. A. S.; MEDEIROS, S. R. A.; MENDONÇA, M. J. N. Adequação de serviços de alimentação às Boas Práticas de Fabricação. Conexões-Ciência e Tecnologia, 14(1), 30-36. 2020.

OLIVEIRA, B. S.; BARBOSA, W. J.; CARDOSO, L. I. Estudo da contaminação de cédulas de dinheiro e moedas por parasitos nas cantinas de uma instituição superior. Vita et Sanitas, 12(2), 110-118. 2018.

ORGANIZAÇÃO MUNDIAL DA SAÚDE; (OMSa). Laboratory testing for coronavirus disease 2019 (COVID-19) in suspected human cases: interim guidance, 2 March 2020. World Health Organization, 2020. Disponível em: https://apps.who.int/iris/bitstream/handle/10665/3313 29/WHO-COVID-19-laboratory-2020.4eng.pdf? sequence $=1 \&$ isAllowed=y. Acesso em 22 de março de 2020. ....

ORGANIZAÇÃO MUNDIAL DA SAÚDE; (OMSb). Coronavirus disease 2019 (COVID-19) Situation Report - $61 . \quad$ Disponível em: https://www.who.int/docs/defaultsource/coronaviruse/situation-reports/20200322sitrep-62-covid-19.pdf?sfvrsn=f7764c46_2. Acesso em: 22 de março de 2020.

PARRY, Jane. China coronavirus: cases surge as official admits human to human transmission. 2020 .

PERLMAN, Stanley. Another decade, another coronavirus. 2020.

PHAN, L. T.; NGUYEN, T. V.; LUONG, Q. C.; NGUYEN, T. V.; NGUYEN, H. T.; LE, H. Q.; PHAM, Q. D. Importation and human-to-human transmission of a novel coronavirus in Vietnam. New England Journal of Medicine, 382(9), 872-874. 2020.

RAMADAN, N.; SHAIB, H. Middle East respiratory syndrome coronavirus (MERS-CoV): A review. Germs, v. 9, n. 1, p. 35. 2019. 
RIOU, J.; ALTHAUS, C. L. Padrão da transmissão precoce de humano para humano do novo coronavírus Wuhan 2019 (2019-nCoV), dezembro de 2019 a janeiro de 2020. Eurosurveillance, 25 (4). 2020.

ROWE, G.; BOLGER, F. Final report on 'the identification of food safety priorities using the Delphi technique'. EFSA Supporting Publications, v. 13, n. 3, p. 1007E. 2016

SABRIÀ, A.; PINTÓ, R. M.; BOSCH, A.; BARTOLOMÉ, R.; CORNEJO, T.; TORNER, N.; GUIX, S. Norovirus shedding among food and healthcare workers exposed to the virus in outbreak settings. Journal of Clinical Virology, 82, 119-125. 2016.

SANTOS, V. F.; CUNHA, G. H.; GALVÃO, M. T. G.; LIMA, I. C. V.; GIR, E.; COSTA, A. K. B. Efeito do uso de álcool em pessoas vivendo com HIV/aids: revisão integrativa. Revista Eletrônica de Enfermagem, 20. 2018.

SHEN, K.; YANG, Y.; WANG, T.; ZHAO, D.; JIANG, Y.; JIN, R.; SHANG, Y. Diagnosis, treatment, and prevention of 2019 novel coronavirus infection in children: experts' consensus statement. World Journal of Pediatrics, 1-9. 2020.

SHEREEN, M. A.; KHAN, S.; KAZMI, A.; BASHIR, N.; SIDDIQUE, R. COVID-19 infection: origin, transmission, and characteristics of human coronaviruses. Journal of Advanced Research. 2020.

SOUZA, D. H. Update on foodborne viruses: molecular-based detection methods. In Advances in
Microbial Food Safety (pp. 117-148). Woodhead Publishing. 2015.

VAN DOREMALEN, N.; BUSHMAKER, T.; MORRIS, D. H.; HOLBROOK, M. G.; GAMBLE, A.; WILLIAMSON, B. N.; LLOYD-SMITH, J. O. Aerosol and Surface Stability of SARS-CoV-2 as Compared with SARS-CoV-1. New England Journal of Medicine. 2020.

VENTURA, D. F. L.; AITH, F. M. A.; RACHED, D. H. "A emergência do novo coronavírus e a "lei de quarentena" no Brasil". Revista Direito e Práxis, Ahead of print, Rio de Janeiro. 2020.

WANG, C.; HORBY, P. W.; HAYDEN, F. G.; GAO, G. F. A novel coronavirus outbreak of global health concern. The Lancet, 395(10223), 470-473. 2020.

WANG, D.; HU, B.; HU, C.; ZHU, F.; LIU, X.; ZHANG, J.; ZHAO, Y. Clinical characteristics of 138 hospitalized patients with 2019 novel coronavirusinfected pneumonia in Wuhan, China. Jama. 2020.

WU, D.; WU, T.; LIU, Q.; YANG, Z. The SARSCoV-2 outbreak: what we know. International Journal of Infectious Diseases. 2020.

YOO, Jin-Hong. The fight against the 2019-nCoV outbreak: an arduous march has just begun. Journal of Korean Medical Science, v. 35, n. 4. 2020.

ZHOU, P.; YANG, X. L.; WANG, X. G.; HU, B.; ZHANG, L.; ZHANG, W.; CHEN, H. D. A pneumonia outbreak associated with a new coronavirus of probable bat origin. Nature, 1-4. 2020. 